\title{
Comparison of the Effectiveness Simvastatin gel 2,5\% and Platelet-rich fibrin (PRF) in Full-thickness Wound Healing of White Rats (Rattus norvegicus)
}

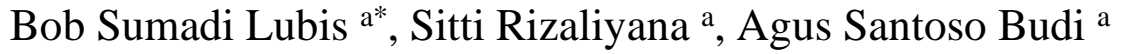 \\ a bobsumadilubis@gmail.com \\ Department of Plastic Reconstructive and Aesthetic Surgery, Faculty of Medicine Airlangga University, Surabaya, Indonesia
}

\begin{abstract}
Background: Wound healing is a complex process, relates to wound care methods, wound dressing materials, to wound closure according to the reconstruction ladder. Research on dressing materials for full-thickness wounds is increasingly diverse, from herbs, medicinal active ingredients, to tissue engineering. Platelet-rich fibrin (PRF) as a second generation of platelet derivatives, plays an important role in inflammatory, proliferative, remodeling processes in wound healing. Simvastatin, an anti-hyperlipidemic drug, in its development has a pleiotropic effect, can reduce inflammation, increase proliferation, thereby accelerating wound healing by increasing angiogenesis. This study aims to compare the effectiveness of Simvastatin gel 2.5\% with Platelet-rich fibrin (PRF) against angiogenesis, fibroblast proliferation, collagen fiber density, and epithelialization rate. Methods: Thirty six rats were randomly divided into three groups. A $2 \times 2$ $\mathrm{cm}$ full-thickness wound was made on the back of the Winstar mouse. Group A was a control group, the wounds were applied with Carboxymethylcellulose (CMC gel). In group B, the wound was treated with Platelet-rich fibrin (PRF), and in group C, the wound was given Simvastatin gel with $2.5 \%$ concentrate. The wounds in each group were dressed with a dressing. Furthermore, the rats were sacrificed on the $3^{\text {rd }}$ and $7^{\text {th }}$ day after treatment, and the samples were taken. Result. There was a significant difference ( $\mathrm{p}<0.05)$, which showed better effectiveness in angiogenesis, fibroblast proliferation, and epithelialization rate of wounds treated with Simvastatin gel 2,5\%. Conclusion: Simvastatin gel with a concentrate of $2.5 \%$ accelerates wound healing, but still requires further research, especially the right concentration so that it can be applied properly in humans.
\end{abstract}

Keywords: Simvastatin; wound healing; full-thickness wound.

\section{INTRODUCTION}

Wounds are a problem that is often faced by a surgeon, both acute wounds caused by trauma, surgery, or chronic wounds due to systemic disorders and other causes. Many factors can interfere with the healing process and cause an increase in the length of healing time, an increase in morbidity and mortality (Young \& McNaught, 2011).

Wound dressing modalities for wound healing are always developing. The use of Platelet-rich fibrin (PRF), which is the second generation of platelet-rich plasma (PRP), is obtained in a simpler, faster way, and without the need for additional materials such as anticoagulants. Platelet-rich fibrin (PRF) contains a variety of growth factors that can be produced from -granule platelets including TGF- $\beta$, PDGF, VEGF, ECGF, -FGF, IGF-1, to stimulate the wound healing process (Sclafani, 2011). 
Statins as a class of drugs known as anti-hyperlipidemia, were found to have a pleiotropic effect. Statins can reduce inflammation and accelerate wound healing by increasing angiogenesis and lymphangiogenesis in wounds. Topical administration of Simvastatin for wound healing can be used to avoid drug side effects caused by systemic administration (Stojadinovic, 2010; Asai, 2012). This study compared the effectiveness of giving Simvastatin gel 2.5\% with the administration of Platelet-rich fibrin (PRF) on wound healing from the aspect of angiogenesis, fibroblast proliferation, collagen density, and speed of epithelialization in the treatment of full-thickness wounds in Wistar rats.

\section{SUBJECTS AND METHOD}

This study used 36 white rats (Rattus norvegicus), male wistar strain of 40-60 days-old with a weight of 200$250 \mathrm{~g}$. To fulfill internal validity, samples were selected and divided into 6 groups randomly. All procedures performed in this study were obtained by the Ethics Commission of the Faculty of Veterinary of Airlangga University with the No. 2. KE. 206. 12. 2019.

Platelet-rich fibrin (PRF) that will be used is allogenic, obtained from the blood of a number of experimental animals (out of the number of samples) that were sacrificed, for intra-cardiac blood collection of 4-5 cc, then processed immediately after the blood is drawn into in a tube without anticoagulant. The tube is placed into a centrifuge machine at a speed of 3000 revolutions per minute (rpm) for 10 minutes. When finished, several layers will form. The red base layer contains red blood cells followed by the top layer of cellular plasma. Between the two layers is the fibrin clot, which is the PRF.

Simvastatin used in this study Simvastatin in the form of a gel preparation, which is produced by the Faculty of Pharmacy, Universitas Airlangga with a concentration of $2.5 \%$. Simvastatin $2.5 \%$ gel is made by dissolving 2.5 grams of Simvastatin (a generic brand of tablet preparation on the market), into $2.5 \mathrm{cc}$ of $70 \%$ ethanol then added to $2.5 \%$ Carboxymethylcellulose (CMC gel) to form a gel precipitate which is used for research.

All rats were anesthetized using injection of Ketamine $75-100 \mathrm{mg} / \mathrm{kgBW}+$ xylazine $10 \mathrm{mg} / \mathrm{kgBW}$ intra peritoneal. Each rat was shaved on the back, and made a square wound design measuring $2 \times 2 \mathrm{~cm}$ on the back and disinfected with Betadine ${ }^{\circledR} 10 \%$. Full-thickness wounds were made by excision using a number 15 knife. The wounds in sample groups 1 and 2 were treated with Simvastatin $2.5 \%$ gel; wounds in sample groups 3 and 4 were treated with Platelet-rich fibrin (PRF); and wounds in sample groups 5 and 6 were treated with CMC gel. The wound was then treated in a closed manner using a transparent polyurethane-based dressing and wrapped with rolled gauze so that it would not come off. All rats were given intramuscular injection of Penicillin Procaine 100 mg/kgBW. 


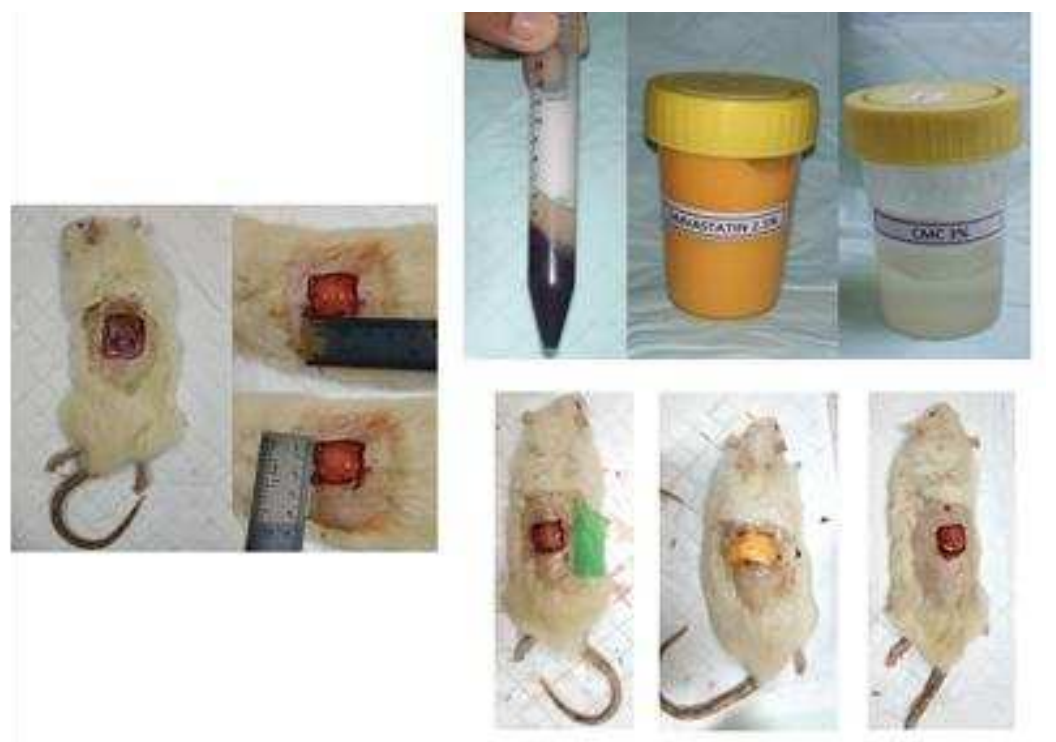

Figure 1. Wound measurement and treatment for each group

On the $3 \mathrm{rd}$ and 7 th day after treatment, the mice were sacrificed by injecting phenobarbital $60-100 \mathrm{mg} / \mathrm{kgBW}$. Wounds on the backs of mice were evaluated for the rate of epithelialization on days 3 and 7 using Visitrax ${ }^{\circledR}$ digital. Biopsy taken from a $2 \times 2 \mathrm{~cm}$ wound and then put it in a vial containing $10 \%$ formalin buffer for tissue fixation. All specimens were prepared by taking specimens from the wound edges, then paraffin blocks were made and stained with Hematoxyllin-Eosin and Mallory Trichome were examined under a light microscope by Anatomical Pathology laboratory staff. Examination by Anatomical Pathology laboratory officers was carried out using a light microscope (Olympus BX51) with a magnification of 400x. The measurement results were then analyzed using a different test (average) with the ANOVA variance test on the SPSS software ver. 21.

This study is an experimental research. Randomized post-test only control group design was used as research design since the initial measurements were not possible. The results of this study were calculated as a mean and standard deviation. Kolmogorrov Smirnov normality test was carried out and continued with the Levene's Test homogeneity test. Furthermore, to test the differences between groups, one way ANOVA test was used with a significance level of $\alpha$ of 0.05 . If there is a difference, it was then proceeded with the Tukey HSD test to determine the differences in each group.

\section{RESULTS}

Angiogenesis is the process of forming new blood vessels, in this study, the number of lumens of blood vessels in the preparation was calculated, and erythrocyte cells were found in the lumen.. 


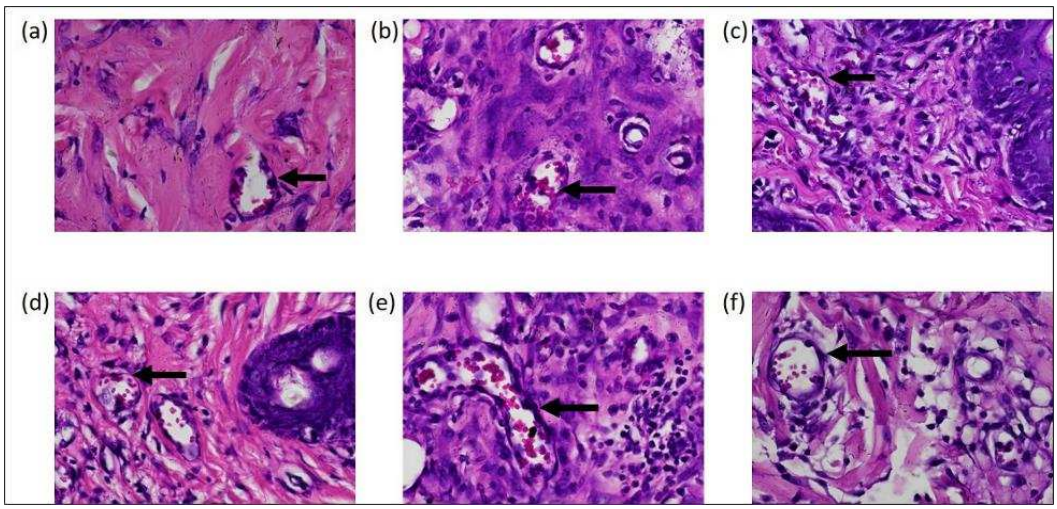

Figure 2. Number of vessel lumens (indicated by black arrows) at: (a) CMC day-3; (b) Simvastatin gel 2.5\% day-3; (c) PRF day-3; (d) CMC day-7; (e) Simvastatin gel 2.5\% day-7; (f) PRF day-7.

Fibroblast proliferation was expressed in the number of fibroblast cells found in 5 visual field sites. The preparations were stained with hematoxylin-eosin, and using a 400x magnification microscope, the number of fibroblasts on the right, middle and left edges of the wound was counted in each preparation..
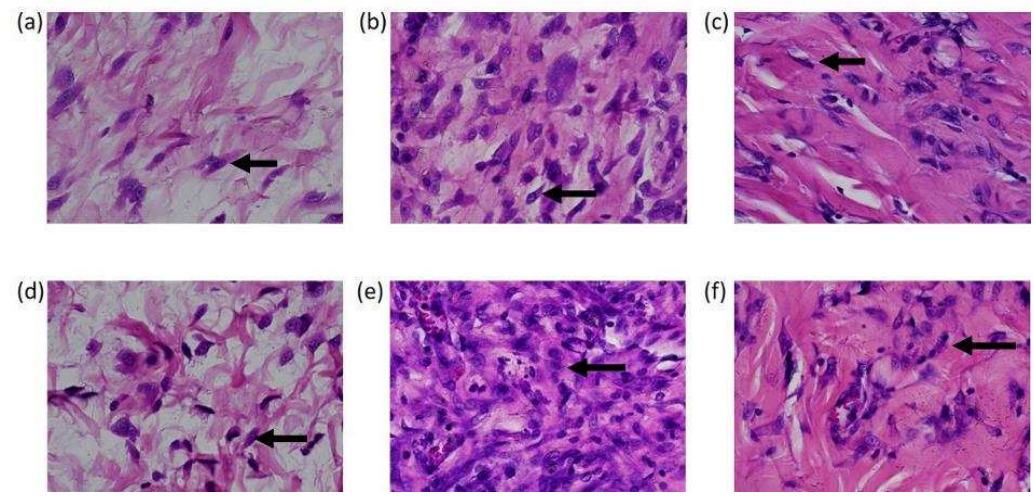

Figure 3. Fibroblast proliferation (indicated by black arrows) at: (a) CMC day-3; (b) Simvastatin gel 2.5\% day-3; (c) PRF day-3; (d) CMC day-7; (e) Simvastatin gel 2.5\% day-7; (f) PRF day-7.

Collagen density was expressed in terms of the number of collagen fibers found in 5 visual fields. To be able to calculate this, the preparations were stained with Mallory Trichrome, and examined using a 400x magnification microscope. Collagen density in this study, was given a score of 1 , if the collagen fibers are loose where the diameter of the collagen fibers is smaller than the width of the distance between the collagen fibers; score 2, if the collagen fibers are moderate where the diameter of the collagen fibers is the same as the width of the distance between the collagen fibers; and a score of 3 , if the collagen fibers are dense where the diameter of the collagen fibers is greater than the width of the distance between the collagen fibers. 


\section{(a)}
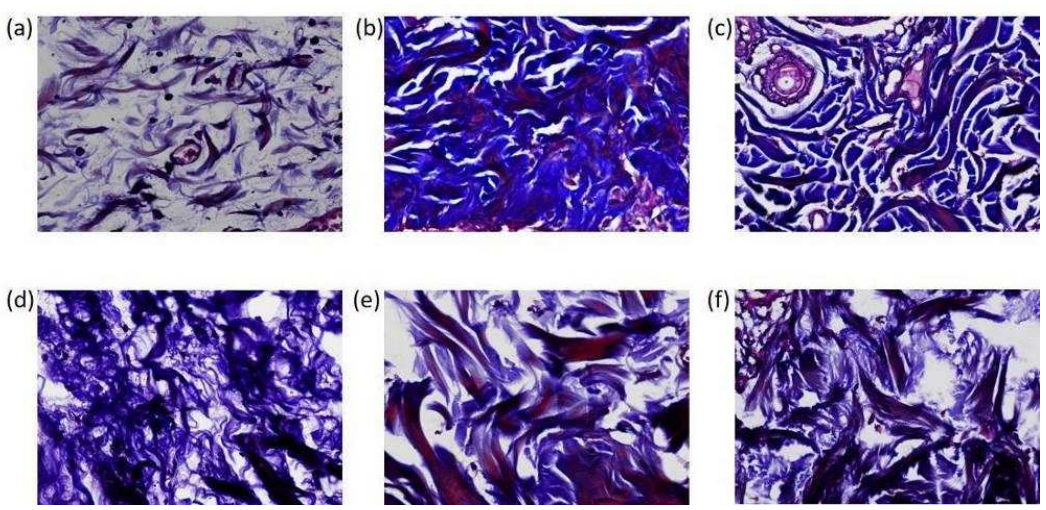

Figure 4. Collagen density (indicated by black arrows) at: (a) CMC day-3; (b) Simvastatin gel 2.5\% day-3; (c) PRF day-3; (d) CMC day-7; (e) Simvastatin gel 2.5\% day-7; (f) PRF day-7.

The speed of epithelialization is the surface area where the wound closure process occurs compared to the time required for the process, with units of $\mathrm{mm} /$ day. Measurements using Visitrax ${ }^{\circledR}$ digital will produce units of area, then converted to millimeters per day.
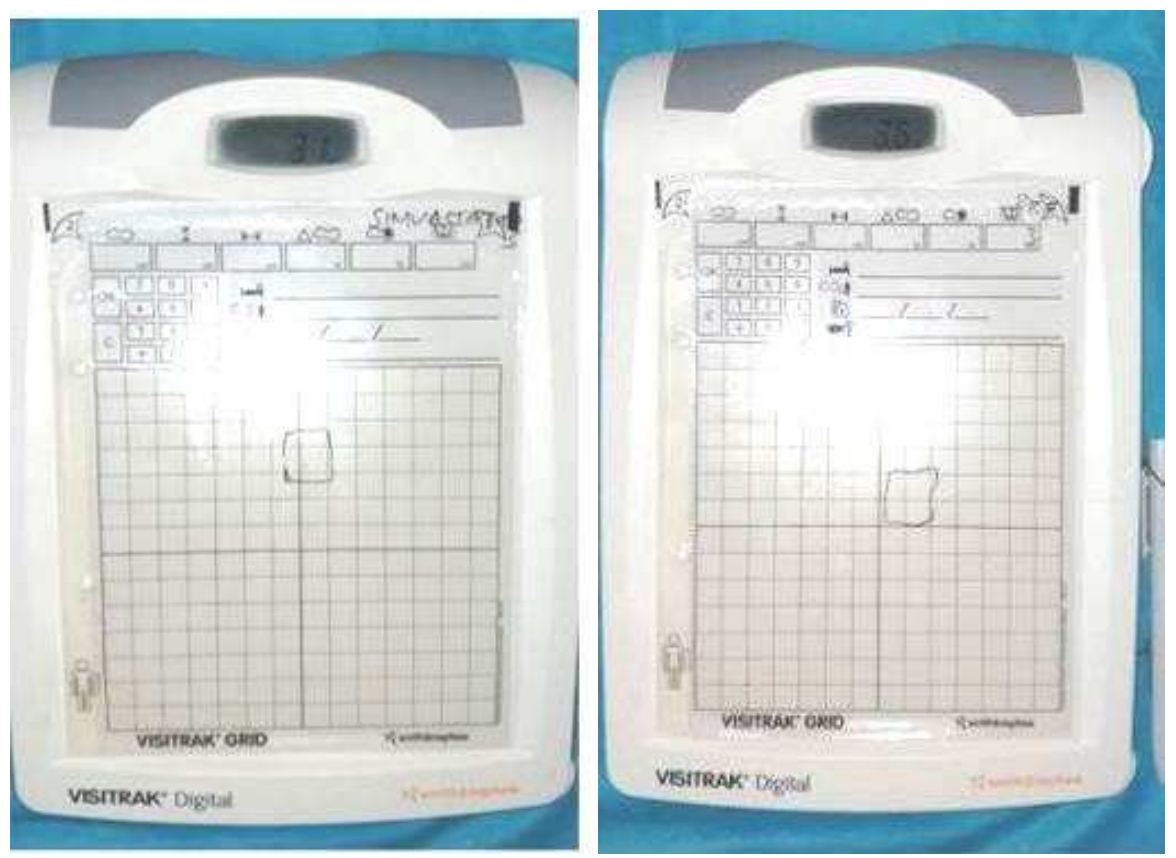

Figure 5. Epithelialization in digital Visitrak $®$ measurements

\section{DISCUSSION}


This study aimed to assess the effect of giving Simvastatin gel 2.5\% compared with platelet-rich fibrin (PRF) in the treatment of full-thickness wounds by assessing angiogenesis, fibroblast proliferation, collagen density, speed of epithelialization, which occurred on day 3 and day 3.7 which represents the wound healing phase. The research subjects were full-thickness wounds on the back of the skin of mice with a size of $2 \times 2 \mathrm{~cm}$, the study population was grouped by: carboxymethylcellulose (CMC) gel group (control group); Simvastatin gel $2.5 \%$; and the platelet-rich fibrin (PRF) group, with randomization.

In this study, angiogenesis that occurred after treatment with Simvastatin gel $2.5 \%$ was suspected as the effect of increasing angiogenesis by increasing progenitor cell activity in endothelial cells. This is in accordance with the statement by Stojadinovic et al. (2010). This result is also in accordance with the research conducted by Asai et al. (2012) that topical Simvastatin can increase angiogenesis and even lymphangiogenesis in healing rat back skin on days 7 and 14 after treatment. Increased vascular perfusion can make Simvastatin a good agent to inhibit wound pathogenesis. Simvastatin can also stimulate angiogenesis by modulating the serine/threonine protein kinase Akt pathway that stimulates nitric oxide.

Khoshneviszadeh et al. (2014) in their study found that there was an increase in fibroblast proliferation as much as $95 \%$ higher in full-thickness wounds after being given Simvastatin gel 2.5\%, compared to the CMC gel treatment. Meanwhile, the pleitropic effect of NO (Nitric oxide) produced by statins can be related to the stimulatory effect on fibroblast activity or indirect effects such as vasodilation and cytokine expression (Schwentker \& Billiar, 2003; Laufs, 2003).

Collagen is the most abundant protein in body tissues, including skin. Collagen is what allows the formation of tensile strength in the skin. Collagen synthesis occurs in the remodeling phase. After the wound is covered with granulation and after the migration of keratinocytes leads to the re-epithelialization process, the remodeling phase begins. Collagen synthesis phase is a phase that does not stand alone but overlaps with other phases (Gurtner, 2014). The results of this study are not in accordance with the results of research conducted by Khoshneviszadeh et al. (2014), that there is a significant increase in collagen density after administration of topical Simvastatin at a level of $2 \%$, where observations were made on day 12 , and it is possible that in the proliferative phase there are more collagen fibers. While in this study, observations were made on the 3rd and 7th day. It is possible that differences in the concentration of topical Simvastatin used may also have an effect.

The wound healing process begins with an inflammatory phase which is influenced by the activation of platelets, neutrophils and macrophages whose levels increase up to 5 or 7 days after the injury. In the proliferative phase, this factor will be replaced by wound healing cell growth factor. The increase in epithelialization that occurred after treatment with Simvastatin gel 2.5\% was thought to occur as an effect of the statin content which inhibits HMG-CoA reductase, thereby reducing mevalonate formation. Simvastatin can reduce endogenous FPP levels so that it can increase keratinocyte migration (in vitro) and the epithelialization process (ex vivo) (Stojadinovic, et al. 2010). 


\section{References}

Asai, J., Takenaka, H., Hirakawa, S., Sakabe, J., Hagura, A., Kashimoto, S., Maruyama, K., Kajiya, K., Kinoshita, S., Tokura, Y., \& Katoh, N., 2012. Topical simvastatin accelerates wound healing in diabetes by enhancing angiogenesis and lymphangiogenesis, American Journal of Pathology, 181(6): pp. 2217 - 2224. https://doi.org/10.1016/j.ajpath.2012.08.023. PMID: 23138019.

McGrath, J.A., \& Breathnach, S.M., 2004. Wound healing. In: T. Burns, S., Breathnach, N. Cox, \& C. Griffiths, eds., Rook's Textbook of Dermatology, 7th ed., Oxford, UK: Wiley-Blackwell Publishing, pp. $357-382$.

Bhanot, S., \& Alex, J.C., 2002. Current applications of platelet gels in facial plastic surgery. Facial Plastic Surgery, 18(1): pp. 27 - 33. https://doi.org/10.1055/s-2002-19824. PMID: 11823930.

Bielecki, T., \& Ehrenfest, D.M.D., 2012. Platelet-rich plasma (PRP) and platelet-rich fibrin (PRF): surgical adjuvants, preparations for in situ regenerative medicine and tools for tissue engineering. Current Pharmaceutical Biotechnology,13(7):pp:1121-1130. https://doi.org/10.2174/138920112800624292. PMID: 21740380.

Chu, D.H., \& David, H., 2008. Development and structure of skin. In: K. Wolff, L.G. Goldsmith, S.I. Katz, B.A. Glichrest, A.S. Paller, \& D.J. Leffell, eds., Fitzpatrick's Dermatology in General Medicine, 7th ed., New York: McGraw-Hill Publishing.

Ehrenfest Dohan DM, Choukroun J, Diss A, et al. Platelet-rich fibrin (PRF): A second-generation platelet concentrate. Part III: Leucocyte activation: A new feature for platelet concentrates? Oral Surgery, Oral Med Oral Pathol Oral Radiol Endodontology. 2006;101(3) doi:10.1016/j.tripleo.2005.07.010

Ehrenfest Dohan Ehrenfest DM, Del Corso M, Diss A, Mouhyi J, Charrier J-B. Three-Dimensional Architecture and Cell Composition of a Choukroun's Platelet-Rich Fibrin Clot and Membrane. J Periodontol. 2010;81(4):546-555. doi:10.1902/jop.2009.090531

Falanga, V., 2004. The chronic wound: impaired healing and solutions in the context of wound bed preparation. Blood Cells, Molecules, and Diseases, 32(1): pp. 88-94. https://doi.org/10.1016/j.bcmd.2003.09.020. PMID: 14757419.

Folkman, J., \& Shing, Y., 1992. Angiogenesis. Journal of Biological Chemistry, 267(16): pp. 10931-10934. PMID: 1375931.

Gaw, A., Packard, C.J., \& Shepherd, J., 2004. Statins: The HMG-CoA Reductase Inhibitors in Perspective, 2nd ed., London: Martin Dunitz, CRC Press.

Ghanaati, S., Booms, P., Orlowska, A., Kubesch, A., Lorenz, J., Rutkowski, J., Landes, C., Sader, R., Kirkpatrick, Cj., \& Choukroun, J., 2014. Advanced platelet-rich fibrin: a new concept for cell-based tissue engineering by means of inflammatory cells. Journal of Oral Implantology, 40(6): pp. 679-689. https://doi.org/10.1563/aaid-joi-D-14-00138. PMID: 24945603.

Gurtner, G.C., \& Wong, V.W., 2014. Wound healing: normal and abnormal. In: C.H.M. Thorne, G.C. Gurtner, K.C. Chung, A. Gosain, B. Mehrara, P. Rubin, \& S.L. Spear, eds., Grabb and Smith's Plastic Surgery, 7th ed., Philadelphia: Lippincott Williams \& Wilkins, pp. 13-19.

Khoshneviszadeh, M., Ashkani-Esfahani, S., Namazi, M.R., Noorafshan, A., Geramizadeh, B., \& Miri, R., 2014. Topical simvastatin enhances tissue regeneration in full-thickness skin wounds in rat models. Iranian Journal of Pharmaceutical Research, 13(1): pp. 263-269. https://doi.org/10.22037/ijpr.2014.1414.

Laufs, U., 2003. Beyond lipid-lowering: effects of statins on endothelial nitric oxide. European Journal of Clinical Pharmacology, 58(11): pp. 719-731. https://doi.org/10.1007/s00228-002-0556-0. PMID: 12634978.

Park, K.W., Hwang, K.K., Cho, H.J., Hur, J., Jang, H.M., Yoon, C.H., Kang, H.J., Oh, B.H., Park, Y.B., \& Kim, H.S., 2008. Simvastatin enhances endothelial differentiation of peripheral blood mononuclear cells in hypercholesterolemic patients and induces proangiogenic cytokine IL-8 secretion from monocytes. Clinica Chimica Acta, 388(1-2): pp. 156-166. https://doi.org/10.1016/j.cca.2007.10.027. PMID: 18037374.

Petzelbauer P., Loewe R., Pober J.S., 2012. Endothelium in Inflammation and Angiogeneisis. In: K. Wolff, L.A. Goldsmith, S.L. Katz, B.A.Gilchrest, A.S. Paller, \& D.J. Leffell, eds., Fitzpatrick's Dermatology in General Medicine, 8th ed., New York: McGraw-Hil.

Rizk, M., Witte, M.B., \& Barbul, A., 2004. Nitric oxide and wound healing. World Journal of Surgery, 28(3): pp. 301-306. https://doi.org/10.1007/s00268-003-7396-7. PMID: 14961192.

Saluja, H., Dehane, V., \& Mahindra, U., 2011. Platelet-rich fibrin: a second generation platelet concentrate and a new friend of oral and maxillofacial surgeons. Annals of Maxillofacial Surgery, 1(1): pp. 53-57. https://doi.org/10.4103/2231-0746.83158. PMID: 23482459.

Sclafani, A.P., 2011. Safety, efficacy, and utility of platelet-rich fibrin matrix in facial plastic surgery. Archieves of Facial Plastic Surgery, 13(4): pp. 247 - 251. https://doi.org/10.1001/archfacial.2011.3. PMID: 21339469.

Sirtori, C.R., 2014. The pharmacology of statins, Pharmacological Research, 88: pp. 3-11. https://doi.org/10.1016/j.phrs.2014.03.002. PMID: 24657242

Singh S., Young, A., \& McNaught, C.E., 2011. The physiology of wound healing. Surgery Oxfort, 29(10): pp. $473-477$. https://doi.org/10.1016/j.mpsur.2017.06.004.

Stojadinovic, O., Lebrun, E., Pastar, I., Kirsner, R., Davis, S.C.,, \& Tomic-Canic, M., 2010, Statins as potential therapeutic agents for healing disorders, Expert Review of Dermatology, 5(6): pp. 689 - 698. https://doi.org/10.1586/edm.10.60 
Wang, C.C., Yang, P.W., Yang, S.F., Hsieh, K.P., Tseng, S.P., \& Lin, Y.C., 2016. Topical simvastatin promotes healing of staphylococcus aureus-contaminated cutaneous wounds. International Wound Journal, 13(6): pp. 1150 - 1157. https://doi.org/10.1111/iwj.12431. PMID: 25752328.

Young, A. and McNaught, C.-E. 2011. The physiology of wound healing. Surgery (Oxford) 29(10), pp. 475-479.

Zhao, Q., Ding, Y.J., \& Si, T., 2013. Platelet-rich fibrin in plastic surgery, Open Access Evidence-Based Medicine, 1(1): p. 1 - 6. 